\title{
APPLICATION OF CHEMOMETRIC METHODS FOR THE DETERMINATION OF CIPROFLOXACIN HYDROCHLORIDE AND PHENAZOPYRIDINE HYDROCHLORIDE IN THEIR PHARMACEUTICAL DOSAGE FORM
}

\author{
M.M. Patel*, U.H. Shah, K. Goswami, S. Bhavsar and S.G. Patel \\ Ramanbhai Patel College of Pharmacy, Charotar University of Science and Technology, \\ CHARUSAT Campus, Changa-388 421, (Gujarat), India \\ *E-mail: mehulpatel.ph@charusat.ac.in
}

\begin{abstract}
For simultaneous analysis of Ciprofloxacin Hydrochloride (CIP), phenazopyridine Hydrochoride (PHE), in its drugdose type, chemometric-assisted UV spectrophotometric methods have been established and validated. The chemometric methods used were partial least square (PLS) regression, principal component regression (PCR) and classical least square (CLS) models. Two sets of standard mixtures, calibration sets and validation sets have been prepared. All three models have been optimized to quantify each drug in the mixture using the information included in the UV absorption spectra of the appropriate solution in the range of 205-515 nm with the range of $5 \mathrm{~nm}$. Optimized models have been successfully applied to the simultaneous estimation of these drugs in synthetic mixture and pharmaceutical dosage form. The methods were validated in linearity, precision, sensitivity, specificity and robustness in the range of $5-25 \mu \mathrm{g} / \mathrm{ml}$ for CIP and $4-20 \mu \mathrm{g} / \mathrm{ml}$ for PHE for spectrophotometric-assisted UV chemometrics as per the ICH guideline. The PLS, PCR, CLS methods developed were used to determine CIP and PHE in tablets.
\end{abstract}

Keywords: Ciprofloxacin Hydrochloride (CIP), Phenazopyridine Hydrochloride (PHE), Chemometrics, UV Spectrophotometric.

() RASĀYAN. All rights reserved

\section{INTRODUCTION}

Ciprofloxacin Hydrochloride (CIP), chemically 1-cyclopropyl-6-fluoro-1, 4-dihydro-4-oxo-7-(1piperazinyl)-3-quinoline carboxylic acid monohydrochloride monohydrate, is a fluoroquinolone class and the structure is shown in Fig.-1. CIP is official in Indian Pharmacopoeia (Indian Pharmacopoeia 2010), British Pharmacopoeia (British Pharmacopoeia 2004), and United State Pharmacopoeia (United State Pharmacopeia 2012). It is a broad-spectrum anti-infective agent that is used in the treatment of different pathological conditions like bacterial conjunctivitis, corneal ulcer, bacterial infection of the respiratory tract, urinary tract infection. The literature survey revealed that there are several analytical methods reported for CIP either individually such as spectrophotometric method ${ }^{1}$, RP-HPLC $^{2}$ or in combination with other drugs by spectrophotometric method ${ }^{3-4}$ and RP-HPLC ${ }^{5}$. Phenazopyridine Hydrochloride (PHE) is chemically 3-(phenylazo)-2, 6-pyridine diamine monohydrochloride and the structure is shown in Figure 1(b). It is broadly used as urinary tract mucosal anesthesia or analgesia for relief in pain, burning and other discomfort resulting from irritation of the lower urinary tract mucosa caused by infection, trauma conditions. PHE is official in United States Pharmacopoeia. The literature survey revealed that there are several analytical methods have been employed for the quantification of PHE either individually such as HPLC in human plasma ${ }^{6}$ and force acid and heat degradation by HPLC ${ }^{7}$ or in combination with other drugs by chemometrics ${ }^{8}$, Spectrophotometric and HPLC ${ }^{9}$ The combination of CIP and PHE is used for the treatment of urinary tract infection. The combination of CIP and PHE has been commercially available in the tablet dosage form.

CIP and PHE analysis in combination can not be carried out without separation by direct UV spectrophotometry, because their UV spectrum is overlapping. For the study of drug substances by

Rasayan J. Chem., 13(4), 2361-2369(2020)

http://dx.doi.org/10.31788/ RJC.2020.1345941

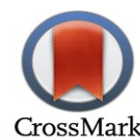


RASĀYAN J. Chem.

Vol. 13 | No. 4 |2361-2369| October - December | 2020

multicomponent using the spectrophotometric technique, chemometrics approach, multivariate calibration method, is applied. The Partial Least Square (PLS) ${ }^{10}$, Principal Component Regression (PCR) and Classical Least Square (CLS) techniques are full-spectrum methods ${ }^{11}$, more effective than those based on single or dual wavelength measurements, such as direct spectrophotometry, simultaneous equation or absorption ratio method, since the simultaneous inclusion of multiple spectral intensities can greatly enhance performance. ${ }^{12-14}$

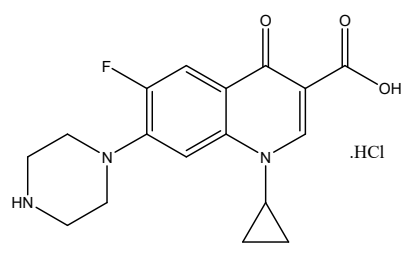

(a)

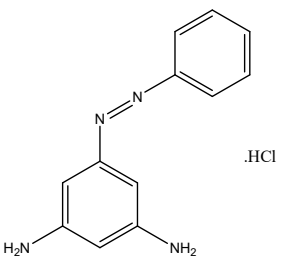

(b)

Fig.-1: Chemical Structure of (a) Ciprofloxacin Hydrochloride and (b) Phenazopyridine Hydrochloride

This study aims to implement a spectrophotometric chemometric approach for the CIP and PHE analysis in tablets. The tablet sample was tested using the spectrophotometric approach optimized by chemometrics. Also, this work is the first application of multivariate calibration methods, principle component regression method (PCR) and partial least square regression (PLS-1), Classical least square (CLS) for quantifying CIP and PHE combination on the tablet.

\section{EXPERIMENTAL}

\section{Material and Methods}

A pharmaceutically pure CIP sample was acquired as a free sample from Zydus Cadila Healthcare Ltd., Ahmedabad and PHE from Sris Pharmaceuticals, Hyderabad. Methanol was purchased from Loba chemicals, Mumbai, India. Glass distillation assembly of Durga scientific, Vadodara was used to prepare triple distilled water. Marketed formulation UTIStat ${ }^{\circledR}$ containing $250 \mathrm{mg}$ of CIP and $200 \mathrm{mg}$ of PHE procured from local market.

\section{Instrumentation and Software}

Shimadzu UV-1800, UV-Visible double beam spectrophotometer with matching $1 \mathrm{~cm}$ quartz cuvette (Shimadzu Corporation, Kyoto, Japan) was used to record UV spectra of solutions. The width of the spectral band is $0.5 \mathrm{~nm}$. Unscrambler ${ }^{\circledR}$ and MICROSOFT EXCEL were used for PCR and PLS model development and data analysis, and Matlab ${ }^{\circledR}$ and MICROSOFT EXEL were used for CLS model development and data analysis.

\section{General Procedure \\ Preparation of Standard Solutions}

The CIP powder (100 mg) has been precisely measured into a $100 \mathrm{~mL}$ flask. It was dissolved and diluted to $100 \mathrm{~mL}$ with methanol to obtain a CIP stock solution with a final concentration of $1 \mathrm{mg} / \mathrm{mL}$, while PHE powder $(100 \mathrm{mg})$ was carefully weighed and transferred to a $100 \mathrm{~mL}$ volumetric flask. It was dissolved and diluted to $100 \mathrm{~mL}$ with methanol to obtain a PHE stock solution with a final concentration of $1 \mathrm{mg} / \mathrm{mL}$.

\section{Preparation of Working Standard Solutions}

The standard CIP $(10 \mathrm{~mL})$ solution has been transferred to the $100 \mathrm{~mL}$ volumetric flask and diluted with $100 \mathrm{~mL}$ methanol for the preparation of the working standard solution of CIP with the final $100 \mu \mathrm{g} / \mathrm{mL}$ concentration.

The standard PHE solution $(10 \mathrm{~mL})$ has been transferred with methanol into a $100 \mathrm{~mL}$ volumetric bottle and diluted with methanol to achieve the standard working PHE solution with a final concentration of $100 \mu \mathrm{g} / \mathrm{mL}$. 
RASĀYAN J. Chem.

Vol. 13 | No. 4 |2361-2369| October - December | 2020

\section{Calibration of PLS, PCR, CLS Methods \\ One Component Calibration}

Calibration of one variable was performed to find the dynamic linear concentration range of each drug. The range of 5-25 $\mu \mathrm{g} / \mathrm{ml}$ for CIP and 4-20 $\mu \mathrm{g} / \mathrm{ml}$ for PHE has been studied for Linear Dynamic Ranges. Absorption values in a $1 \mathrm{~cm}$ quartz cell against methanol as blank were recorded as $\lambda \max (281 \mathrm{~nm}$ CIP and $414 \mathrm{~nm}$ PHE). For each compound, the linear dynamic range was calculated by the least-square linear concentration regression and the resulting absorption.

\section{Binary Standard Solutions}

Two sets of standard solutions were planned calibration set and validation set. Fourteen calibration specifications and eight testing level mixtures were prepared by combining appropriate quantities of CIP and PHE working standard solutions and dilution to methanol quantities. This demonstrated the combination of CIP and PHE in Table-1. The spectra of absorption of prepared solutions were measured at an interval of $5 \mathrm{~nm}$ from 205-505 $\mathrm{nm}$. Calibration collection absorbance data were subjected to Unscambler ${ }^{\circledR}$ for PLS, PCR and Matlab ${ }^{\circledR}$ for CLS models. The concentration of CIP and PHE in the validation set was predicted with the use of proposed PLS, PCR and CLS models to test these PLS, PCR and CLS models.

Table-1: Composition of the Calibration Set and Validation Set

\begin{tabular}{|c|c|c|}
\hline Std. No. & $\mathrm{CIP}(\mu \mathrm{g} / \mathrm{ml})$ & PHE $(\mu \mathrm{g} / \mathrm{ml})$ \\
\hline $1 \mathrm{C}$ & 5 & 12 \\
\hline $2 \mathrm{C}$ & 5 & 16 \\
\hline $3 \mathrm{C}$ & 5 & 24 \\
\hline $4 \mathrm{C}$ & 10 & 4 \\
\hline $5 \mathrm{C}$ & 10 & 8 \\
\hline $6 \mathrm{C}$ & 10 & 24 \\
\hline $7 \mathrm{C}$ & 15 & 4 \\
\hline $8 \mathrm{C}$ & 20 & 8 \\
\hline $9 \mathrm{C}$ & 20 & 12 \\
\hline $10 \mathrm{C}$ & 20 & 16 \\
\hline $11 \mathrm{C}$ & 20 & 20 \\
\hline $12 \mathrm{C}$ & 20 & 24 \\
\hline $13 \mathrm{C}$ & 25 & 20 \\
\hline $14 \mathrm{C}$ & 25 & 24 \\
\hline $1 \mathrm{~V}$ & 10 & 20 \\
\hline $2 \mathrm{~V}$ & 15 & 8 \\
\hline $3 \mathrm{~V}$ & 15 & 16 \\
\hline $4 \mathrm{~V}$ & 15 & 20 \\
\hline $5 \mathrm{~V}$ & 15 & 24 \\
\hline $6 \mathrm{~V}$ & 20 & 4 \\
\hline $7 \mathrm{~V}$ & 20 & 8 \\
\hline $8 \mathrm{~V}$ & 25 & 16 \\
\hline
\end{tabular}

$*_{\mathrm{c}}=$ Solution of calibration set, $\mathrm{v}=$ Solution of validation set

\section{Analysis of marketed formulation}

Twenty tablets were measured and finely powdered. Tablet powder equal to $100 \mathrm{mg}$ Ciprofloxacin hydrochloride was correctly weighed and transferred to $100 \mathrm{~mL}$ volumetric flask and added $50 \mathrm{~mL}$ of methanol. Sonicated for $20 \mathrm{~min}$, the mixture was diluted with methanol (Solution A) to the mark and filtered through Whatman filter paper No. $41,10 \mathrm{ml}$ aliquot was separated from this Solution A into 100 
RASĀYAN J. Chem.

Vol. 13 | No. 4 |2361-2369| October - December | 2020

$\mathrm{ml}$ flask and diluted with methanol (Solution B). From this Solution B, $0.5 \mathrm{ml}$ aliquot was inserted into 10 $\mathrm{ml}$ volumetric flask and diluted as the final test solution using methanol for chemometrics (Solution $\mathrm{C}$ had $5 \mu \mathrm{g} / \mathrm{ml} \mathrm{CIP}$ and $4 \mu \mathrm{g} / \mathrm{ml}$ PHE). Concentration CIP and PHE were identified using established calibration model PCR, PLS and CLS for chemometrics.

\section{Detection Method}

\section{Chemometrics Methods}

CIP and PHE chemical structures are shown in Fig.-1 whereas Fig.-2 Shows UV spectra and combination of medications. As this figure indicates, they overlap. Such drugs' spectral similarity prohibits mixture resolution through direct spectrophotometric measurements.

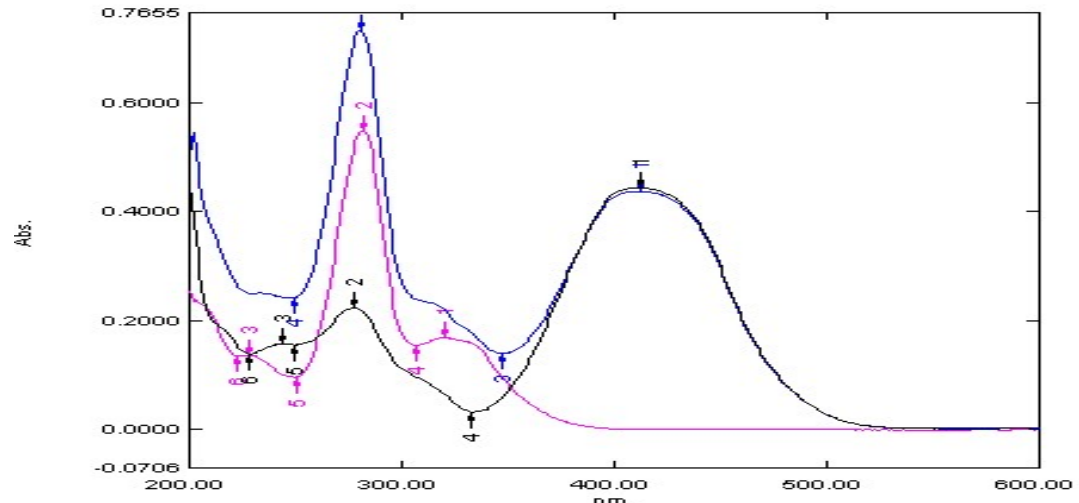

Fig.-2: Overlain Spectra of CIP, PHE and their Mixture One Component Calibration

To find each component's linear dynamic range, calibration graphs were obtained. Absorption spectra were reported over 200-600 nm against a blank solvent. For each compound, the linear range was calculated by plotting the absorbance at its $\lambda \max$ (CIP, $281 \mathrm{~nm}$ and PHE, $414 \mathrm{~nm}$ ) versus sample concentration. Calibration curves were linear between 5.0-25 $\mu \mathrm{g} / \mathrm{ml} \mathrm{CIP}$ and 4.0-20.0 $\mu \mathrm{g} / \mathrm{ml}$ PHE. Characteristic parameters for individual calibration regression equations are shown in Table-2.

Table-2: Characteristic Parameters for the Regression Equations of Individual Calibration by Absorption Spectra

\begin{tabular}{c|c|c|c|c}
\hline Comp. & Regression Equation & $\mathrm{r} 2$ & SD of slope & SD of intercept \\
\hline CIP & $\mathrm{Y}=0.039 \mathrm{x}-0.002$ & 0.996 & 0.00669 & 0.0253 \\
\hline PHE & $\mathrm{Y}=0.082 \mathrm{x}+0.019$ & 0.999 & 0.00584 & 0.0201 \\
\hline
\end{tabular}

\section{Multivariate Methods}

The first step in multivariate methods involved constructing the calibration matrix. The wavelength range used was 205 to $515 \mathrm{~nm}$. Sixty-three spectral points with $5 \mathrm{~nm}$ intervals were selected within this range. The composition of calibration mixtures was random.

Designed to obtain full information from the mixtures' spectra. The efficiency of the study of multiple components depends on the range of wavelength and spectrum mode. The UV spectrum of CIP, PHE and mixture are shown in the Fig.-2. The calibration set and validation set were prepared randomly with the CIP and PHE methanol mixtures (Table-1). The absorbance was observed inside the region between 200$600 \mathrm{~nm}$ at the wavelength point of 63 in the region between 205-515 nm with an interval of $5 \mathrm{~nm}$.

The model PCR and PLS were developed by the program Unscrambler ${ }^{\circledR}$ and the model CLS was developed by the program Matlab $\AA$. The development of the model was carried out using calibration standards. The LOO-CV was used in the development of the model to validate PCR, PLS and CLS models, and to obtain latent equilibrium variables (number of factors) of the model. A cross-validation approach was used with high calibration spectra to pick the optimally latent variables (number of factors) in the PLS, PCR and CLS algorithms. Each sample has been compared to actual component 
RASĀYAN J. Chem.

Vol. 13 | No. 4 |2361-2369| October - December | 2020

concentrations for each validation sample and each test the root average cross-validation square error (RMSECV) is determined. The RMSECV was used to check the error in expected concentrations as a diagnostic tool. This model is important if PLS, PCR and CLS calibrations are to be quantified correctly. Table-3 displays the parameters of optimal models. The resulting models were also validated by predicting the analyte concentration in a separate validation method not used in the design of the model. Tables- 4 and 5 demonstrate the outcomes of the forecast and the rate of recoveries. Assessing the predictive ability of the model was carried out with the plotting of the actual known concentrations against predicted concentrations and the plot of the actual known concentrations against the expected concentrations is stated in Fig.-3. As observed, the predicted(calculated) was consistent with the actual drug concentration. Recoveries of means and the relative standard deviation from our proposed methods have been estimated and shown for CIP and PHE in Tables-4 and 5. In the validation package, optimized PLS, PCR and CLS models suggesting the strong predictive capacity of the models were provided with satisfactory correlation coefficient ( $\mathrm{r} 2$ ) values for-compound. Another diagnostic test was performed by measuring the residual concentrations against the concentrations expected. The residuals are distributed uniformly about zero, suggesting appropriate models. Table- 6 shows the statistical parameters of the validation package.

\section{Analytical Discussion}

Statistical Analysis ${ }^{15}$

The ability to calibrate can be described in many ways. For this article, the figures were determined for the standard variation of the chemometric calibrations in the case of the mixtures examined. The following expression shows the normal calibration error (SEC) and prediction:

$(\mathrm{SEP}) \cdot \operatorname{SEC}(\mathrm{SEP})=\sqrt{\frac{\sum_{i=1}^{n}\left(\mathrm{c}_{\mathrm{i}}^{\text {Added }}-\mathrm{c}_{\mathrm{i}}^{\text {Found }}\right)^{n}}{n-1}}$

Here, CiAdded represents the added concentration, $\mathrm{Ci}$ Found denotes the determined concentration and $\mathrm{n}$ is the total number of samples. The numerical values of SEC were indicated in Table 3. The SEP of the same mixtures is displayed in Table-3.

The prediction residual error sum-of-squares (PRESS) of the calibration step was calculated as:

PRESS $=\sum_{i=1}^{n}\left(C_{i}^{\text {Added }}-C_{i}^{\text {Found }}\right)^{2}$

The root mean squares error of cross-validation (RMSECV) was calculated for each method as follows:

$$
\text { RMSECV }=\sqrt{\frac{\text { PRESS }}{\mathrm{n}}}
$$

Where, $\mathrm{n}=$ number of predicted samples

\section{Recovery Study}

\section{RESULTS AND DISCUSSION}

For calibration purposes, the zero-order absorbance measured on selected wavelength ranges is used and used in PLS, PCR, CLS calibrations. The quantity of each drug was calculated in the synthetic mixture prediction (validation). Table-7 and Table- 8 display the findings of the recovery analysis.

\section{Analysis of Market Formulation}

UV-assisted chemometrics was used for the study of URISTAT ${ }^{\circledR}$ marketed formulation, reporting 250 $\mathrm{mg}$ for CIP and $200 \mathrm{mg}$ for PHE per tablet. The drug check findings are consistent with the label statement (Table-9). 
RASĀYAN J. Chem.

Vol. 13 | No. 4 |2361-2369| October - December | 2020

Table-3: Statistical Parameters of Optimum PLS, PCR and CLS Models for the Calibration Set

\begin{tabular}{|c|c|c|c|c|c|c|}
\hline \multirow{2}{*}{ Parameter } & \multicolumn{3}{|c|}{ CIP } & \multicolumn{3}{|c|}{ PHE } \\
\hline & PLS & PCR & CLS & PLS & PCR & CLS \\
\hline Range $(\mu \mathrm{g} / \mathrm{ml})$ & \multicolumn{3}{|c|}{$5-25$} & \multicolumn{3}{|c|}{$4-20$} \\
\hline Wavelength Region (nm) & \multicolumn{3}{|c|}{$205-515$} & \multicolumn{3}{|c|}{$205-515$} \\
\hline$\Delta \lambda(\mathrm{nm})$ & \multicolumn{3}{|c|}{5} & \multicolumn{3}{|c|}{5} \\
\hline Factor & 7 & 7 & - & 7 & 7 & - \\
\hline $\mathrm{SD}$ & 1.46 & 1.44 & 1.34 & 1.32 & 1.40 & 1.09 \\
\hline Correlation Coefficient (r2) & 0.997 & 0.997 & 0.998 & 0.999 & 0.999 & 0.999 \\
\hline Intercept & -0.366 & -0.368 & 0.450 & -0.059 & -0.066 & -0.066 \\
\hline Slope & 1.023 & 1.023 & 0.974 & 0.998 & 0.997 & 0.997 \\
\hline RMSECV & 0.0609 & 0.0659 & 1.0230 & 0.0889 & 0.0993 & 0.2553 \\
\hline RMSEP & 0.2923 & 0.2893 & 0.2191 & 0.2093 & 0.2025 & 0.1689 \\
\hline
\end{tabular}

Table-4: Results of the Prediction Set of CIP by PLS, PCR and CLS Methods

\begin{tabular}{c|c|c|c|c|c|c|c|c|c}
\hline \multirow{2}{*}{$\begin{array}{c}\text { CIP } \\
(\mu \mathrm{g} / \mathrm{ml})\end{array}$} & \multicolumn{3}{|c|}{ Predicted Conc. } & \multicolumn{3}{c|}{ \% Recovery } & \multicolumn{3}{c}{ Residual } \\
\cline { 2 - 11 } & PLS & PCR & CLS & PLS & PCR & CLS & PLS & PCR & CLS \\
\hline 10 & 10.01 & 10.01 & 9.97 & 100.10 & 100.10 & 99.78 & -0.010 & -0.010 & 0.022 \\
\hline 15 & 15.01 & 15.02 & 15.14 & 100.13 & 100.18 & 100.98 & -0.020 & -0.026 & -0.146 \\
\hline 15 & 14.82 & 14.83 & 15.00 & 98.87 & 98.90 & 100.01 & 0.173 & 0.164 & -0.001 \\
\hline 15 & 14.73 & 14.74 & 15.38 & 98.20 & 98.29 & 102.55 & 0.269 & 0.256 & -0.382 \\
\hline 15 & 15.26 & 15.25 & 15.13 & 101.73 & 101.72 & 100.93 & -0.266 & -0.258 & -0.139 \\
\hline 20 & 20.29 & 20.28 & 20.04 & 101.45 & 101.45 & 100.25 & -0.297 & -0.289 & -0.049 \\
\hline 20 & 19.67 & 19.67 & 19.60 & 98.35 & 98.38 & 98.04 & 0.326 & 0.324 & 0.391 \\
\hline 25 & 25.40 & 25.42 & 24.79 & 101.60 & 101.68 & 99.19 & -0.409 & -0.420 & 0.201 \\
\hline \multicolumn{3}{|c|}{ MEAN } & 100.05 & 100.09 & 100.22 & & & \\
\hline
\end{tabular}

Table-5: Results of the Prediction Set of PHE by PCR, PLS and CLS Methods

\begin{tabular}{c|c|c|c|c|c|c|c|c|c}
\hline \multirow{2}{*}{$\begin{array}{c}\text { PHE } \\
(\mu \mathrm{g} / \mathrm{ml})\end{array}$} & \multicolumn{3}{|c|}{ Predicted Conc. } & \multicolumn{3}{c|}{ \% Recovery } & \multicolumn{3}{c}{ Residual } \\
\cline { 2 - 11 } & PLS & PCR & CLS & PLS & PCR & CLS & PLS & PCR & CLS \\
\hline 20 & 19.92 & 19.93 & 19.93 & 99.65 & 99.66 & 99.67 & 0.072 & 0.067 & 0.065 \\
\hline 8 & 7.81 & 7.83 & 7.86 & 97.75 & 97.89 & 98.30 & 0.181 & 0.168 & 0.135 \\
\hline 16 & 15.67 & 15.69 & 15.58 & 98.00 & 98.12 & 97.40 & 0.324 & 0.505 & 0.416 \\
\hline 20 & 19.91 & 19.96 & 20.14 & 99.55 & 99.80 & 100.75 & 0.660 & 0.040 & -0.149 \\
\hline 24 & 23.93 & 23.90 & 23.94 & 99.71 & 99.62 & 99.77 & 0.538 & 0.092 & 0.055 \\
\hline 4 & 4.06 & 4.03 & 3.99 & 101.75 & 100.90 & 99.82 & -0.067 & -0.036 & 0.007 \\
\hline 8 & 7.88 & 7.91 & 7.93 & 98.63 & 98.95 & 99.17 & 0.114 & 0.083 & 0.066 \\
\hline 16 & 16.08 & 16.14 & 16.05 & 100.50 & 100.90 & 100.32 & -0.080 & -0.144 & -0.050 \\
\hline \multicolumn{3}{|c|}{ SEAN } & 99.44 & 99.47 & 99.40 & & & \\
\hline \multicolumn{3}{|c|}{$\%$ RSD } & 1.32 & 1.13 & 1.09 & & & \\
\hline
\end{tabular}

Table-6: Statistical Parameters of Optimum PLS, PCR and CLS Models for the Validation Set

\begin{tabular}{|c|c|c|c|c|c|c|}
\hline \multirow[t]{2}{*}{ Parameters } & \multicolumn{3}{|c|}{ CIP } & \multicolumn{3}{|c|}{ PHE } \\
\hline & PLS & PCR & CLS & PLS & PCR & CLS \\
\hline RMSECV & 0.0609 & 0.0659 & 1.0230 & 0.0889 & 0.0993 & 0.2553 \\
\hline RMSEP & 0.2923 & 0.2893 & 0.2191 & 0.2093 & 0.2025 & 0.1689 \\
\hline Slope & 1.023 & 1.023 & 0.974 & 0.998 & 0.997 & 0.997 \\
\hline Intercept & -0.366 & -0.368 & 0.450 & -0.059 & -0.066 & -0.066 \\
\hline R2 & 0.997 & 0.997 & 0.998 & 0.999 & 0.999 & 0.999 \\
\hline
\end{tabular}


RASĀYAN J. Chem.

Vol. 13 | No. 4 |2361-2369| October - December | 2020

Table-7: Result of CIP for Accuracy by PLS, PCR and CLS Models ( $\mathrm{n}=3$ )

\begin{tabular}{c|c|c|c|c|c|c|c|c}
\hline Level & $\begin{array}{c}\text { Sample Conc. } \\
(\mu \mathrm{g} / \mathrm{ml})\end{array}$ & $\begin{array}{c}\text { Standard Added } \\
(\mu \mathrm{g} / \mathrm{ml})\end{array}$ & \multicolumn{3}{|c|}{$\begin{array}{c}\text { Mean Amount } \\
\text { Recovered }(\mu \mathrm{g} / \mathrm{ml})\end{array}$} & \multicolumn{4}{|c}{ \%Mean } \\
\cline { 3 - 9 } & & & PLS & PCR & CLS & PLS & PCR & CLS \\
\hline 50 & 5 & 2.5 & 7.51 & 7.52 & 7.38 & 100.23 & 100.28 & 98.41 \\
\hline 100 & 5 & 5 & 10.03 & 10.05 & 9.87 & 100.37 & 100.52 & 98.72 \\
\hline 150 & 5 & 7.5 & 12.24 & 12.25 & 12.58 & 98.03 & 98.02 & 100.65 \\
\hline
\end{tabular}

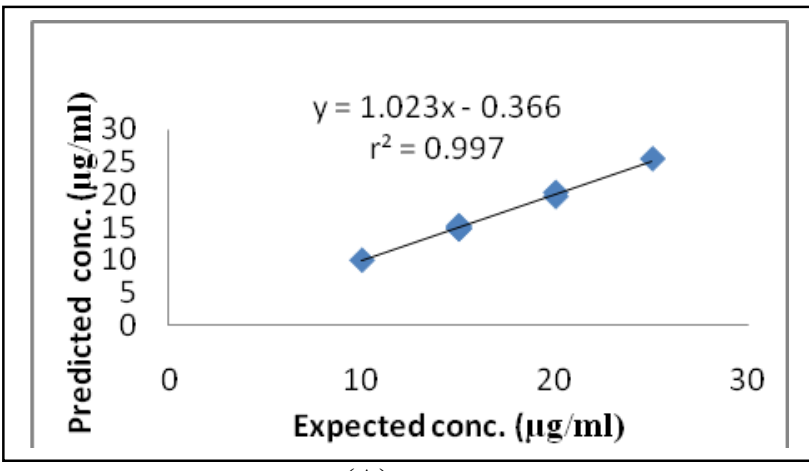

(A)

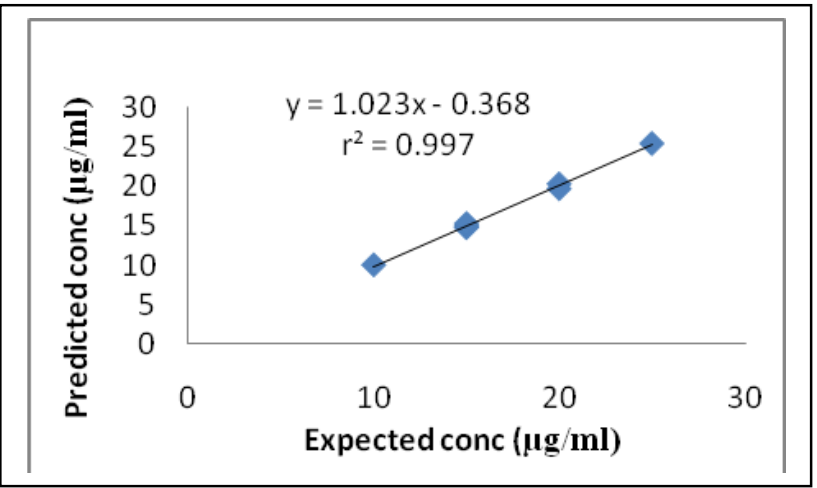

(C)

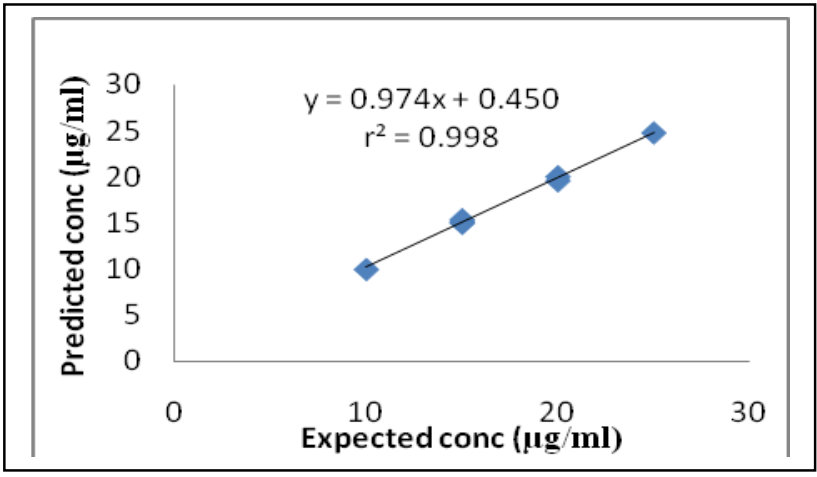

(E)

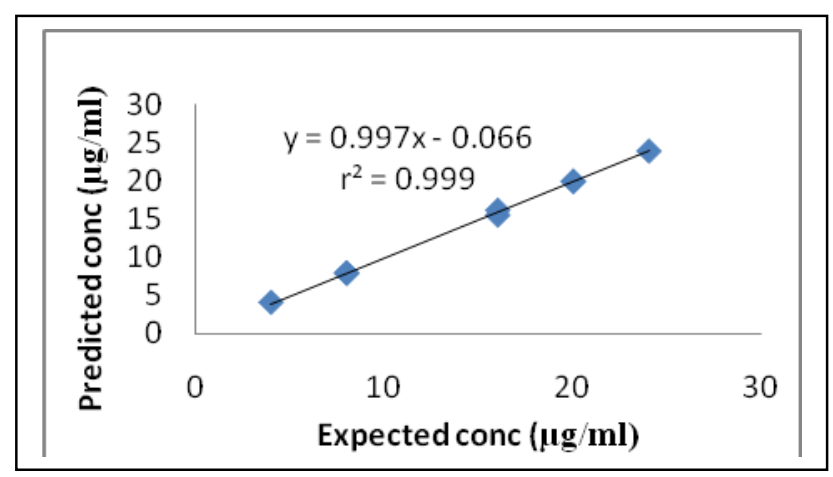

(B)

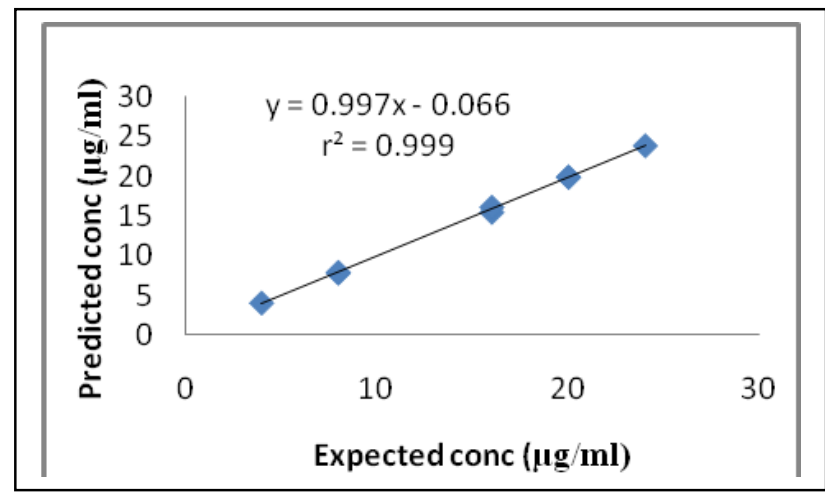

(D)

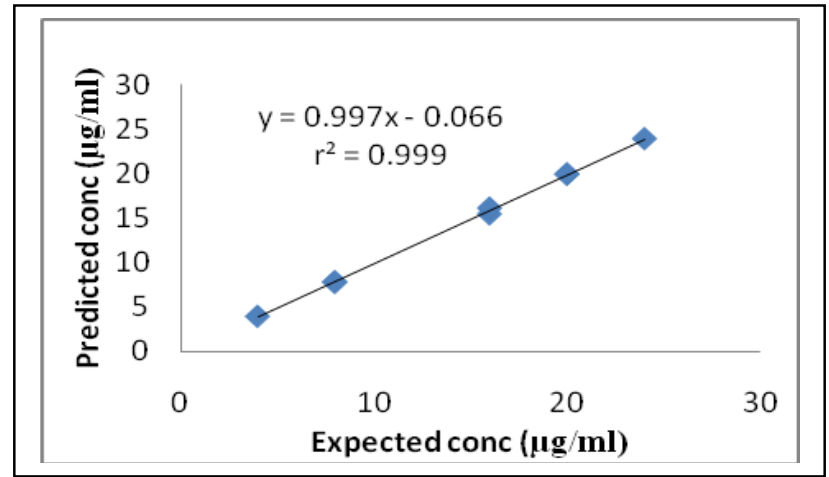

(F)

Fig.-3: Plot of Predicted Vs Known Concentration for (A) CIP and (B) PHE for PLS method, (C) CIP and (D) PHE for PCR method and (E) CIP and (F) PHE for CLS Method

Table-8: Result of PHE for Accuracy by PLS, PCR and CLS Models ( $\mathrm{n}=3$ )

\begin{tabular}{|c|c|c|c|c|c|c|c|c|}
\hline \multirow[t]{2}{*}{ Level } & \multirow{2}{*}{$\begin{array}{l}\text { Sample Conc. } \\
(\mu \mathrm{g} / \mathrm{ml})\end{array}$} & \multirow{2}{*}{$\begin{array}{c}\text { Standard Added } \\
(\mu \mathrm{g} / \mathrm{ml})\end{array}$} & \multicolumn{3}{|c|}{ Mean Amount Recovered $(\mu \mathrm{g} / \mathrm{ml})$} & \multicolumn{3}{|c|}{$\%$ Mean } \\
\hline & & & PLS & PCR & CLS & PLS & PCR & CLS \\
\hline 50 & 4 & 2 & 5.93 & 5.94 & 5.92 & 98.94 & 99.01 & 98.74 \\
\hline 100 & 4 & 4 & 7.84 & 7.85 & 7.84 & 98.02 & 98.03 & 99.13 \\
\hline 150 & 4 & 6 & 9.98 & 10.01 & 10.02 & 99.98 & 100.10 & 100.20 \\
\hline
\end{tabular}


RASĀYAN J. Chem.

Vol. 13 | No. 4 |2361-2369| October - December | 2020

Table-9: Results of the Assay in Commercial Samples

\begin{tabular}{|c|c|c|c|c|c|c|}
\hline \multirow[t]{3}{*}{ Sample No. } & \multicolumn{6}{|c|}{$\%$ Amount Found } \\
\hline & \multicolumn{2}{|c|}{ PLS } & \multicolumn{2}{|c|}{ PCR } & \multicolumn{2}{|c|}{ CLS } \\
\hline & CIP & PHE & CIP & PHE & CIP & PHE \\
\hline 1 & 98.63 & 97.97 & 99.26 & 98 & 99.88 & 98.02 \\
\hline 2 & 98.26 & 98 & 98.88 & 98 & 99.56 & 98.03 \\
\hline 3 & 101.41 & 99.38 & 101.99 & 99.50 & 100.18 & 98.11 \\
\hline 4 & 99.84 & 99.08 & 99.40 & 99.22 & 99.92 & 98.03 \\
\hline 5 & 99.60 & 99.03 & 99.07 & 99.28 & 99.57 & 98.02 \\
\hline 6 & 99.57 & 99.23 & 99.70 & 99.42 & 100.20 & 98.12 \\
\hline Mean & 99.22 & 98.78 & 99.71 & 99.89 & 99.98 & 98.06 \\
\hline SD & 1.16 & 0.64 & 1.15 & 0.72 & 0.28 & 0.04 \\
\hline
\end{tabular}

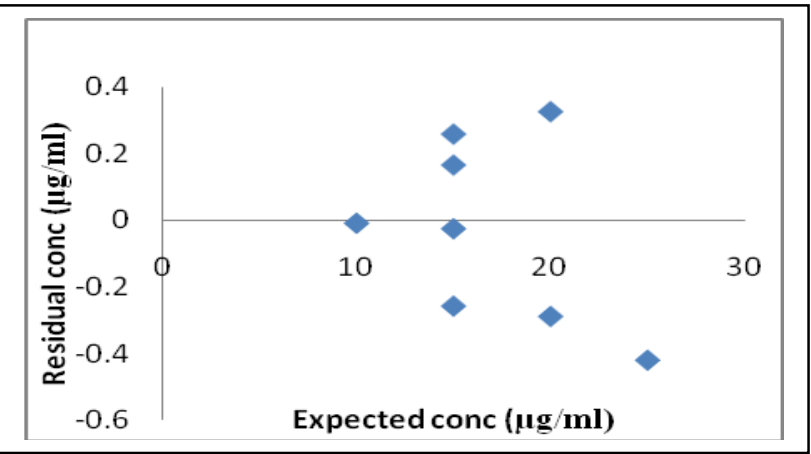

(A)

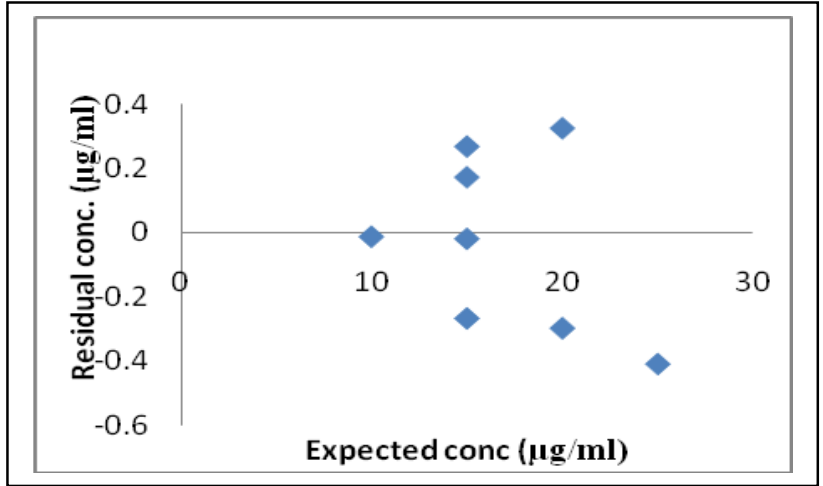

(C)

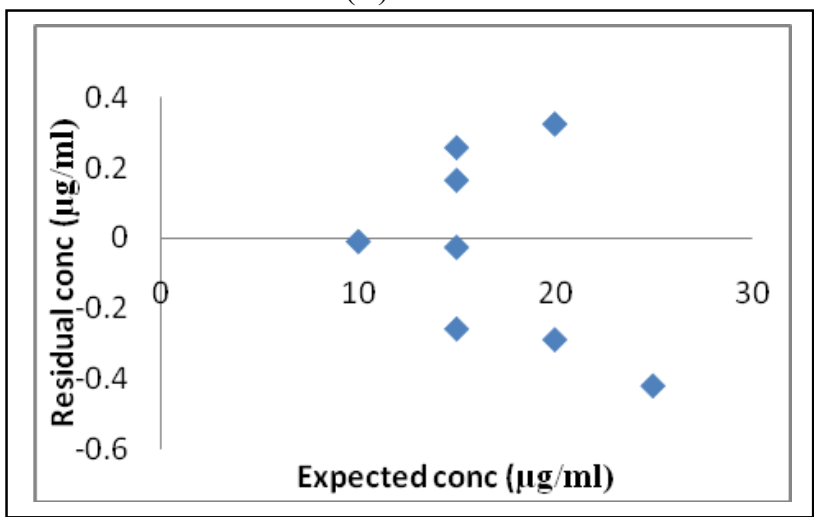

(E)

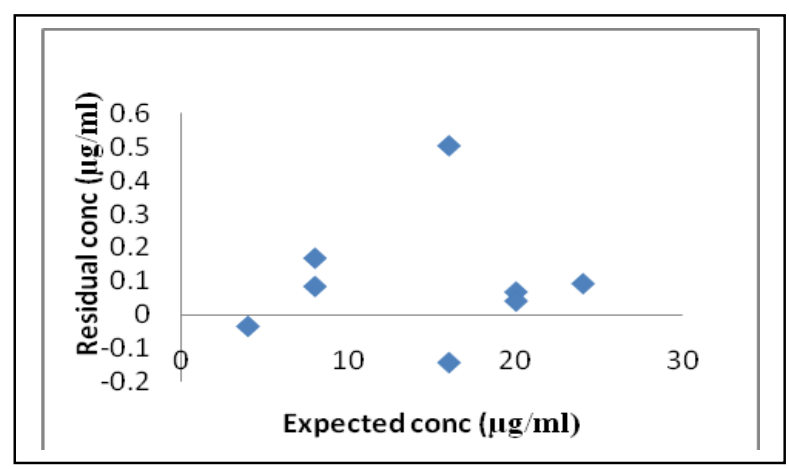

(B)

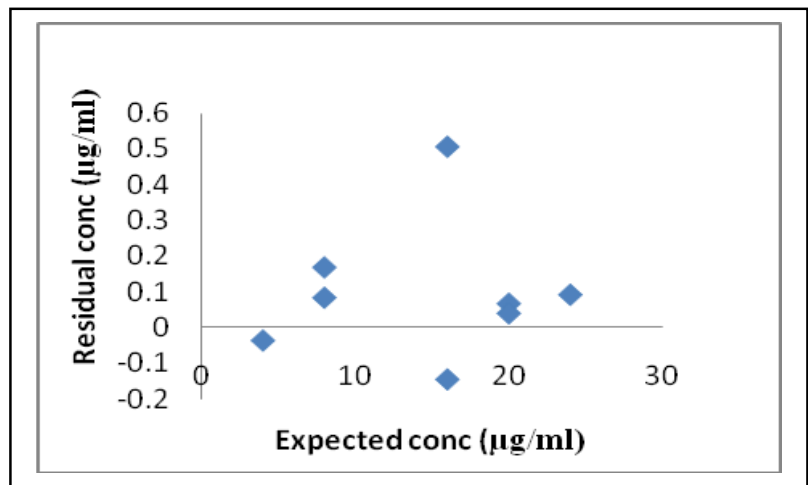

(D)

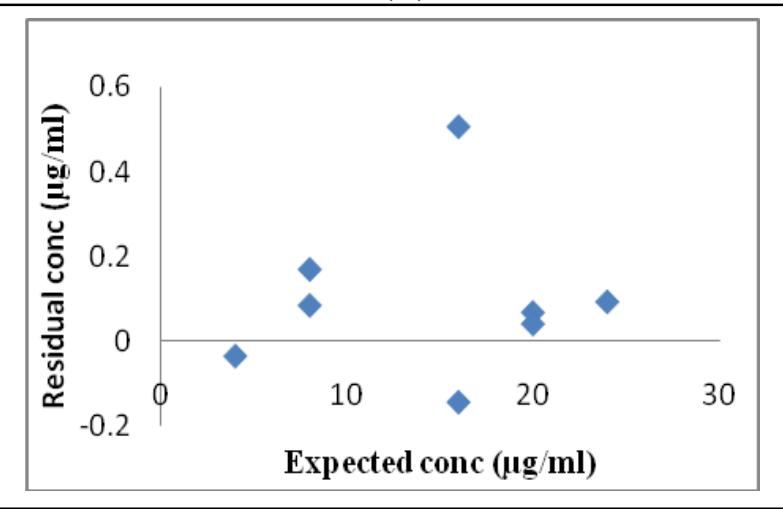

(F)

Fig.-4: Plot of Expected Vs Residual Concentration for (A) CIP and (B) PHE for PLS method, (C) CIP and (D) PHE for PCR method and (E) CIP and (F) PHE for CLS Method 


\section{CONCLUSION}

The Partial least-square regression (PLS), Principal component regression (PCR) and Classical Least square (CLS) models have been successively built in the standard mixing set (validation set) for the determination of CIP and PHE. Three multivariate calibration models achieved equal accuracy. The proposed Chemometric assisted spectrophotometric method in the combination of the pharmaceutical formulation is applicable, rapid and accurate for the simultaneous determination of CIP and PHE. The findings of the testing of commercial formulation obtained using PLS, PCR and CLS models were not substantially different. This means that the proposed PLS, PCR and CLS models should be used in combined pharmaceutical formulation to evaluate the quality of CIP and PHE.

\section{ACKNOWLEDGEMENT}

The authors are thankful to Zydus Cadila Healthcare Ltd., Ahmedabad for providing gratis sample of Ciprofloxacin Hydrochloride and also extended our gratitude to Ramanbhai Patel College of Pharmacy and Charotar University of Science and Technology (CHARUSAT) for providing the facilities for completion of the project.

\section{REFERENCES}

1. M. I. Pascual-Reguera, G. P. Parras and A. M. Diaz, Microchemical Journal, 77(1), 79(2004), DOI: 10.1016/j.microc.2004.01.003

2. R.S. Nijhu, Y.M. Jhanker and K.B. Sutradhar, Stamford Journal of Pharmaceutical Science, 4(1), 84 (2011), DOI:10.3329/sjps.v4i1.8876

3. N. M. Kassab, A. K. Singh E. R.M. Kedor-Hackmam and R. M. Santoro, Revista Brasileira De Ciencia Do Solo, 41(4), 507 (2005), DOI:10.1590/S1516-93322005000400014.

4. J. Singh, A. Jangra, J. Kumar, K. Rani and R. Kumar, Rasayan Journal of Chemistry, 13(1), 105 (2020), DOI:10.31788/RJC.2020.1315382

5. D. Farin, G.Piva and R. Kitzes-Cohen, Chromatographia, 52(3), 180(2000), DOI: $10.1007 / \mathrm{BF} 02490452$

6. L. Fotouhi, Y. Yamini, R. Hosseini and M. Rezazadeh, Canadian Journal of Chemistry, 93(7), 702 (2015), DOI:10.1139/cjc-2014-0460

7. E. Dinç and D. Baleanu, Journal of Pharmaceutical and Biomedical Analysis, 30, 715 (2002), DOI: $10.1016 / \mathrm{S} 0731-7085(02) 00359-\mathrm{X}$

8. A. El-Gindy, S. Emara and H. Shaaban, Journal of Pharmaceutical and Biomedical Analysis, 43, 973 (2007), DOI:10.1016/j.jpba.2006.09.020

9. U. Shah, S. Patel, M. Raval and P. Desai, Indian Journal of Pharmaceutical Education and Research, 49(3), 203(2015), DOI:10.5530/ijper.49.3.5

10. U Shah and A. Jasani, Eurasian Journal of Analytical Chemistry,12(3), 211(2017), DOI: $10.12973 /$ ejac.2017.00164a

11. M. Perez-Cova, R. Tauler and J. Jaumot, Chemometric and Intelligent Laboratory Systems, 201 (2020), DOI:10.1016/j.chemolab.2020.104009

12. S.M. Rid, M.Farid, M.H. Abdel Rahman and D. Atef, Analytical Chemistry Letters, 9(2), 234(2019), DOI: $10.1080 / 22297928.2018 .1548943$

13. S. Shiyan, Firtya, Arimia and G. Pratiwi, Rasayan Journal of Chemistry, 13(3), 1472(2020), DOI: $10.31788 /$ RJC.2020.1335755

14. Muchlisyam, E.S.B Raesa, R. Dathita and S.P. Richa, Rasayan Journal of Chemistry, 12(4), 1693 (2019), DOI:10.31788/RJC.2019.1245428

15. P.Desai, K. Mori and M.Patel, International Journal of Pharmaceutical Sciences Review and Research, 21(1), 296(2013)

[RJC-5941/2020] 